Int. J. Electrochem. Sci., 15 (2020) $3504-3516$

International Journal of

ELECTROCHEMICAL

SCIENCE

WWW.electrochemsci.org

\title{
Corrosion inhibition effect of 1-butyl-3-methyl-1H- benzimidazolium iodide for 2205 duplex stainless steel in hydrochloric acid solution
}

\author{
Xiong Zhang ${ }^{1,3}$, Jiewen Li $^{2}$, Xingwen Zheng ${ }^{2,3, *}$, Min Gong ${ }^{1,3}$, Wilfred Emori ${ }^{3}$, Wenpo Li ${ }^{4}$, \\ Bochuan Tan ${ }^{4}$ \\ ${ }^{1}$ School of Chemical Engineering, Sichuan University of Science \& Engineering, Zigong 643000, \\ China \\ ${ }^{2}$ School of Chemistry and Environmental Engineering, Sichuan University of Science \& Engineering, \\ Zigong 643000, China \\ ${ }^{3}$ Key Laboratory of Material Corrosion and Protection of Sichuan Province, Zigong 643000, China \\ ${ }^{4}$ School of Chemistry and Chemical Engineering, Chongqing University, Chongqing 400044, China \\ *E-mail: zxwasd@126.com
}

doi: $10.20964 / 2020.04 .18$

Received: 7 December 2019 / Accepted: 29 January 2020 / Published: 10 March 2020

\begin{abstract}
The anticorrosion properties of 1-butyl-3-methyl-1H-benzimidazolium iodide (BMBM) for 2205 duplex stainless steel in $1.0 \mathrm{M} \mathrm{HCl}$ solution has been evaluated by electrochemical techniques (potentiodynamic polarization and electrochemical impedance spectroscopy) and scanning electron microscopy. The effect of temperature and concentration on the inhibition efficiency have also been studied. The results reveal that BMBM is a mixed-type inhibitor whose adsorption obeys the Langmuir adsorption isotherm. The inhibition efficiency increased with increase in concentration, but decreased when the temperature was raised. The results obtained from kinetic analysis were compared with those of electrochemical techniques and they confirmed that BMBM is an effective green corrosion inhibitor for 2205 duplex stainless steel in $1.0 \mathrm{M} \mathrm{HCl}$.
\end{abstract}

Keywords: 2205 duplex stainless steel, Hydrochloric acid, Corrosion inhibitor, Adsorption isotherm, Kinetic analysis

\section{$\underline{\text { FULL TEXT }}$}

(C) 2020 The Authors. Published by ESG (www.electrochemsci.org). This article is an open access article distributed under the terms and conditions of the Creative Commons Attribution license (http://creativecommons.org/licenses/by/4.0/). 